\section{MURRAY HILL LABORATORY OF BELL TELEPHONE LABORATORIES}

\section{By FRANKLIN L. HUNT \\ Bell Telephone Laboratories}

A

RURAL location for part of the research and development work of Bell Telephone Laboratories has long been contemplated, and after extensive preparations it has taken form at Murray Hill, New Jersey, about twenty-five miles from New York City. In a group of new buildings there, on a 200 -acre site bordering a park reservation, are now accommodated about eight hundred of the Laboratories' employees, which now number more than six thousand.

The buildings form an H-shaped structure of buffcoloured brick which provides approximately 215,000 sq. ft. of laboratory area. There is also a separate unit which is $4 \mathrm{ft}$. wide so that it can be interchargad with a partition in any part of the buildings.

Along the outside wall of the buildings there is sheet steel wainscoting under the windows and up the piers between them. This is the same in appearance as the partition panels and it is also stiffened like them with transverse members and coated on the back side with mastic. This wainscoting is removable without special tools to give access to service pipes and wiring behind it. Similar wainscoting is applied around interior columns.

A research laboratory requires many special facilities such as compressed air, vacuum, hydrcgen, oxygen, nitrcgэn and illuminating gas, steam at several pressures, hot, cold, chilled and distilled water, chemical drains, and electric power at different voltages. Fifteen such services are regularly supplied and distributed to individual laboratories at Murray Hill, and there are also special services. The service mains are installed either in the basement or the attic. Risers are grouped at the outside walls and pass up through vertical chases located there at 6 -ft. intervals throughout the buildings. Horizontal runouts below the window-sills pass behind the metal wainscoting and extend all the services into individual laboratories. To gat these services from the risers at the side walls to laboratory benches, special supports were devised for quick attachment to the partitions.

Another method of bringing service pipes into the acoustics building, a boiler house and a garage. 'The main building is in two parallel sections, $675 \mathrm{ft}$. and $340 \mathrm{ft}$. long. These are connected by a 144-ft. transverse building in which the entrance is located. There are also five $50-\mathrm{ft}$. proj scting wings on the two parallel buildings to provide additional space for the offices. Each section of the building has three laboratory and office floors, a cellar and an attic. The latter are used exclusively for piping, pumps, ventilating systems and storage.

Restaurant, cafeteria and luncheon room facilities, with a combined seating capacity of more than four hundred persons, and a kitchen completely furnished with the most up-to-date equipment have been provided. These are essential to the operation of the plant because other eating places are not available in the immediate vicinity.

In designing the Murray. Hill building, plans were made not only to provide laboratory and office space cf any size needed, but also to make quick changes and re-arrangements possible. There are no permanent partitions in the buildings except those around the stair wells, toilets and elevator shafts. All other partitions are built up of standard metal panels $10 \mathrm{ft}$. 8 in. high and, with a few exceptions, $4 \mathrm{ft}$. wide.

The outside surfaces of these units are sheet steel, which is stiffened by transverse members welded to it inside on 9 -in. centres. The steel sides are separated by a 3-in. space which is packed with rock wool to prevent the transmission of sound and heat. The inside surface of the steel is also coated with a deadening material. Doors and transoms are made in one laboratories is through ducts in the floor fill which extend $8 \mathrm{ft}$. into the room from the outer wall. These ducts are installed only when required for 'island' benches located in the centre of the room and are used principally in the chemical laboratories. They have steel covers with open sections where the services turn up at the benches. In the laboratory rooms, electric power is distributed along each wall in a metal trough with removable cover plates which face out so that wiring can be readily changed. These plates are interchangeable and may be either plain or equipped with outlet and protective devices.

Forced ventilation is provided for the chemical laboratories by blower units which take in fresh air, filter and temper it and force it through ducts into each laboratory room. The air is exhausted through the fume hoods by another set of fans. All the ventilating equipment is located in the attic of the chemistry section of the buildings.

An unusual feature at Murray Hill is the distribution of hydrogen, oxygen and nitrogen as well as illuminating gas to individual laboratories by pipes from a central supply. The hydrogen is stored in pressure tanks in one room and the oxygen and nitrogen in another to avoid fire hazard. There is a rate of flow gauge in the hydrogen lines to keep the amount used in any room below that which could form an explosive mixture. All these gases are distributed from the attic to individual laboratories by mains which run the length of the building under the rocf.

The acoustic laboratories are housed in a separate 
building to avoid noise and vibration from other activities. Besides regular laboratory space, this includes a large 'dead' room for response measurements of microphones and loud speakers, two 'live' rooms or reverberation chambers for transmission and absorption measurements and a small auditorium.

The auditorium was built primarily for experiments in auditorium acoustics and its construction follows the latest practice in acoustic treatment. To break up reflections, the side walls are splayed and the rear wall is sloped away from the seats for the same purpose. Panelling at the rear of the room, and that on the adjacent side walls and ceiling, is perforated and backed by absorbing material to reduce reflected sound from these areas. There are 363 seats. Each is upholstered to absorb about as much sound when not occupied as would a person, thus maintaining the same reverberation characteristics in the room whether it is empty or filled to capacity. For the convenience of the audience, the seats are widely separated in accord with European practice. Although made quite reverberant for musical reproduction, the excellent acoustic characteristics of the listening room make it exceptionally satisfactory for speaking. There are no windows. Decorative lights are mounted on the side walls. Recessed lamps are distributed uniformly over the ceiling and spotlights illuminate the platform and speaker. These groups of lights can be used separately or in combination and most of them can also be dimmed.

A technical library is an indispensable adjunct to a research laboratory, and provision has been made at Murray Hill for this need by transferring about eight thousand volumes from the main library at New York City. Reference books and technical periodicals make up most of the collection, since other books are always available on request from New York. The stacks are made of sheet steel with adjustable metal shelves, slotted to prevent the accumulation of dust, and the front edge of the lowest two shelves is tilted upward to aid in reading titles. Along two sides of the room there is a row of small study carrells with chair, writing-table and shelves for the convenience of those who have long assignments and who wish to have several reference books immediately at hand. This is a valuable feature, because it provides privacy and avoids the confusion and disturbance of a common study table.

The additional facilities provided at the Murray Hill Laboratories are in great demand in the present war emergency, and are contributing effectively toward the solution of many problems posed by the conflict. Practically the entire staff is now engaged in war work.

\section{A MYRMECOPHILOUS WOODLOUSE}

$\mathrm{I}^{\mathrm{N}}$ the spring of 1938 Prof. G. E. Hutchinson found a small white blind myrmecophilous sowbug in North Branford, Connecticut. The species was afterwards found in ants' nests in a small tract of country several miles in area round about the original locality, and within the Mt. Carmel region of Hamden, Conn., some nine miles from North Branford.

Prof. J. L. Brooks, in a recent paper (Ecology, 23, No. $4,427-37 ; 1942)$, points out that in 1921 there were five valid species of Platyarthrus, four of these being restricted to the Mediterranean region, and only one, $P$. hoffmanseggi Brdt., being found throughout Europe. In 1931 Archangeli described a new species from the Canary Islands, and in 1934 Demianowicz reported two more from Bessarabia. The Connecticut species was identified as Platyarthrus hoffmanseggi Brdt. Its distribution is given as Upper Italy, Spain, France, Switzerland, Holland, Germany, Denmark, Austria, Hungary, Russia and the British Isles.

North Branford, Conn., is the first place in the New World where a Platyarthrus has been found. In all probability it was accidentally introduced from Europe.

All the species of this genus are myrmecophilous, but most of the observations concerning them are confined to the species in question. Although Was. mann considered $P$. hoffmanseggi to be pan-myrmecophilous, Prof. Brooks says that it has not been recorded with other ants than those he lists. He points out that the records from the Continent are from Archangeli ; and for England from Donisthorpe, and Webb and Sillem. He is indebted to Prof. Neal A. Weber for the names of the ants with which it has been found in America.

Prof. Brooks considers that the data indicate the existence of some factor or factors governing the presence of this sowbug only in the nests of certain species in any region. This is possibly the case; but $I$ am inclined to think that if collectors had always recorded the presence of the crustacean when they had seen it, or had specially looked for it, the number both of localities and species of ants would be considerably greater.

As Mr. Brooks is not a myrmecologist himself, he can be excused for some errors in his list of ants. There are no species called Myrmica rufa, or Formica flava. Also the genus Atta F. only occurs in Texas, Mexico, Central and South America, and has certainly never been recorded from Europe. Atta cephalotes L., not cephalotis, is recorded from the basin of the Amazon, Columbia, Central America, and Mexica. Furthermore, as Prof. Brooks says himself, he has used the generic nomenclature adopted by the Committee of the Royal Entomological Society of London, and thus has been 'let down' about Acanthomyops. For example, A. fuliginosus Latr. belongs to the subgenus Dendrolasius Ruzsky. It could be called, according to whether one accepts Lasius or Acanthomyops as the genus, either Lasius (Dendrolasius) fuliginosus Latr., or Acanthomyops (Dendrolasius) fuliginosus Latr., but never Lasius (Acanthomyops) (see Donisthorpe, Ent. Record, 49, 143 ; 1937). Also flavus F., and umbratus Nyl., belong to the subgenus Chtonolasius Ruzsky. The variety of Formica fusca L. is glebaria Nyl., not gleboris.

We now come to Prof. Brooks' experimental work to endeavour to discover the factors involved in the relationship between the woodlouse and its hosts. These are of a delicate, ingenious, and painstaking nature. They are intended to test the response to light (phototaxis), unoriented response (photoklinokinesis), response to atmospheric humidity gradient, and the reaction to a gradient of formic acid vapour, and are illustrated by diagrams, graphs, histograms, etc. The results are briefly as follows. Platyarthrus hoffmanseggi showed no direct response to light under the conditions used in the experiments. It showed a lower klinokinesis in the light than in the dark, and the klinokinesis of this species was found 